\title{
ULTRASOUND ANALYSIS IN RHEUMATOID ARTHRITIS PATIENTS WITH LOW DISEASE ACTIVITY
}

Clarissa Oliveira Teles (Hospital Geral de Fortaleza, Fortaleza, CE, Brasil), Felipe Peixoto Nobre (Universidade Federal do Ceará, Fortaleza, CE, Brasil), Bianca Castro Martins de Oliveira Teofilo (Universidade Federal do Ceara, Fortaleza, CE, Brasil), Karina Rossi Bonfiglioli (Universidade de São Paulo, São Paulo, SP, Brasil), Jose Alexandre Mendonça (PUC - Campinas, Campinas, SP, Brasil), Ingrid Bandeira Moss (HUCFF - UFRJ, Rio de Janeiro, RJ, Brasil), Kirla Wagner Poti Gomes (Universidade de Fortaleza - UNIFOR, Fortaleza, CE, Brasil), Andre Xenofonte Cartaxo Sampaio (Hospital Geral de Fortaleza, Fortaleza, CE, Brasil)

\section{BACKGROUND}

Rheumatoid arthritis (RA) is a chronic autoimmune inflammatory disease that has exacerbations, defined by clinical parameters and increase of clinical scores that guidetherapeutic management. Clinical manifestations may not correspond to active joint disease, therefore it is still necessary toevaluate markers with better prediction of diseaseactivity. The main purpose of this study is to analyze the presence of active joint disease by ultrasonographic grey scale and Power Doppler in RA patients with low disease activity (LDA) and clinical remission.

\section{MATERIALS AND METHODS}

We selected RA patients with $<10$ points of Clinical Disease Activity Index (CDAI), which were using conventional synthetic DMARDs, without association with biological drugs. They were submitted to grey scale and power doppler ultrasound analyses of PIPs, MCPs, wrists, knees, ankles and MTPs between May to June of 2018. We compared the data between the results of ultrasound with measurements of CDAI.

\section{RESULTS}

27 AR patients were evaluated, of which $88,4 \%$ were female, and $69 \%$ had positive rheumatoid factor. The mean disease time was 11 years. All patients were using methotrexate or leflunomide. $53.84 \%$ had LDA, and $46.15 \%$ were in remission. Those with LDA had CDAI of 5.57 with average of 1.38 on gray scale points of MCP, wrists and MTF, 0.86 points on power Doppler in the joints analyzed, and $42.1 \%$ presented relevant abnormalities on ultrasound. Regarding joint assessment, LDA group had an average of 1,64 tender and 0,64 swollen joints. Patients in remission had CDAl of 1.15, with average of 1.45 gray scale points in the same joints of the first group, 0.59 points on power Doppler, and $66.7 \%$ had relevant manifestations on ultrasound. In this group, the mean number of tender joints was 0.33 and there was no identifiable swollen joints.

\section{CONCLUSION}

A great proportion of RA patients with LDA or even in remission presented abnormalities on evaluation by ultrasound. Joint assessment by this exam may represent a more sensitive method for determining disease activity in these patients, guiding earlier interventions, and preventing joint damage. 